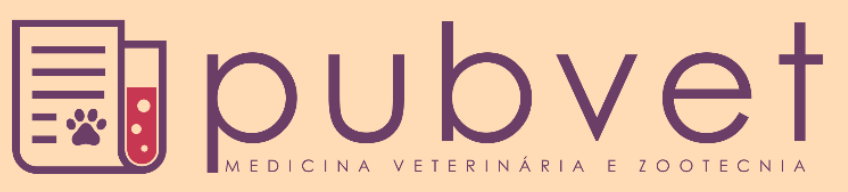

https://doi.org/10.31533/pubvet.v15n06a837.1-8

\title{
O outro lado dos ácidos orgânicos e fitogênicos
}

\author{
Jefferson Bastos Alves ${ }^{\bullet}$, Milton Jiménez Valdiviezo', Caio Abércio da Silva ${ }^{\bullet}$, Ana Paula \\ Frederico Rodrigues Loureiro Bracarense ${ }^{\circ} \odot$
}

${ }^{1}$ Universidade Estadual de Londrina, Campus Universitário, Rodovia Celso Garcia Cid, Km 380, Londrina, Paraná, 86057-970, Brasil

*Autor de Correspondência, E-mail: anapaula@uel.br

Resumo. A produção animal intensiva exige estratégias sanitárias que aliem efetividade e economicidade. A cadeia suinícola exibe produtividade elevada com demandas crescentes no aspecto de saúde animal. A limitação de promotores de crescimento na produção animal gerou a necessidade de substitutos a esses produtos. Os ácidos orgânicos e os fitogênicos têm sido utilizados com este enfoque, sendo pouco explorados ou pouco conhecidos os vários outros benefícios que desenvolvem. O objetivo desta revisão é permitir que sejam conhecidos de forma plena as características pouco tratadas dos ácidos orgânicos e os fitogênicos, potenciais substitutos dos promotores de crescimento.

Palavras-chave: Ácidos orgânicos, antibióticos, fitogênicos, promotores de crescimento, suínos

\section{The other side of organic and phytogenic acids}

Abstract. Intensive animal production requires health strategies that combine effectiveness and economy. The pig chain exhibits high productivity with increasing demands in the aspect of animal health. The limitation of growth promoters in animal production generated the need for substitutes for these products. Organic and phytogenic acids have been used with this focus, and the many other benefits they develop are little explored or little known. The purpose of this review is to allow the poorly treated characteristics of organic acids and phytogenics to be fully known, potential substitutes for growth promoters.

Keywords: Organic acids, antibiotics, phytogenics, growth promoters, swine

\section{La otra cara de los ácidos orgánicos y fitogénicos}

Resumen. La producción animal intensiva requiere estrategias sanitarias que combinen eficacia y economía. La cadena porcina exhibe una alta productividad con demandas crecientes en el aspecto de la salud animal. La limitación de los promotores del crecimiento en la producción animal generó la necesidad de sustitutos de estos productos. Se han utilizado ácidos orgánicos y fitogénicos con este enfoque, y los muchos otros beneficios que desarrollan son poco explorados o poco conocidos. El propósito de esta revisión es permitir que se conozcan completamente las características mal tratadas de los ácidos orgánicos y fitogénicos, posibles sustitutos de los promotores del crecimiento.

Palabras clave: Ácidos orgánicos, antibióticos, fitogénicos, promotores del crecimiento, porcinos

\section{Introdução}

O Brasil, um dos mais importantes players da suinocultura mundial, detém elevados níveis de eficiência e produtividade e cada vez mais mostra-se comprometido com as demandas dos mercados, em especial quanto a qualidade sensorial e de segurança de seus produtos, atendendo o consumidor brasileiro, ainda pouco exigente, e as elevadas exigências dos importadores. 
As tratativas de banimento dos antibióticos promotores de crescimento (APC) das rações representam questões que tangenciam fortemente esta discussão e que deverão, num primeiro momento, se consolidar nos mais rigorosos países produtores e consumidores de carne suína, sendo posteriormente seguido por todos os outros.

Neste contexto, a exclusão dos APC nas granjas, um dos mais efetivos aliados do controle das diarreias, em especial dos animais mais novos, que incrementa o ganho de peso e melhora a conversão alimentar, tem determinado importantes mudanças de estratégia. Assim, é grande a busca por produtos que possam atender estas necessidades e por ações de manejo que, em sinergia, venham a manter os índices de desempenho e de saúde em níveis similares aos registrados com o uso de promotores de crescimento.

Há alguns anos, antecipando-se a este fim irremediável de uso dos APC, vem crescendo o número de empresas e de produtos, tratados como alternativos aos APC, que buscam ocupar esta lacuna. A diversidade de produtos é grande, sendo que a classe dos ácidos orgânicos e dos fitogênicos representa um dos aditivos mais utilizados na produção animal. No entanto, o enfoque dispensado a estes se restringe aos efeitos clássicos que detêm, como as ações bactericidas e bacteriostáticas, sendo pouco explorados ou pouco conhecidos os vários outros benefícios que desenvolvem. Portanto, o objetivo desta revisão é permitir que sejam conhecidos de forma plena as características pouco tratadas destes potenciais substitutos dos APC, os ácidos orgânicos e os fitogênicos.

\section{Ácidos orgânicos e fitogênicos}

Os ácidos orgânicos são produtos que estão presentes nas plantas e nos tecidos animais, sendo constituintes naturais destes ou formados pelo processo de fermentação microbiana no trato gastrintestinal (Gauthier, 2002). Podem, por exemplo, ser encontrados na forma livre (utilizados principalmente como fonte de energia no intestino) e como sais de cálcio e potássio. A vantagem dos sais sobre os ácidos livres é que geralmente são inodoros, pouco voláteis, estão na forma sólida e, portanto, são de fácil manipulação, em especial quando envolvidos na produção de alimentos e de rações. Outra vantagem dos sais de ácidos é que têm pouco ou nenhum efeito corrosivo no trato intestinal, destacando-se o di-propionato de amônia, di-formato de potássio, formato de sódio, propionato de cálcio, lactato de cálcio, formato de amônia e outros mais (Paul et al., 2007). Entre os ácidos mais utilizados temos: o ácido fórmico, acético, propiônico, butírico, lático, málico, benzoico, sórbico, fumárico e cítrico, sendo os quatro últimos encontrados na forma sólida (Partanen \& Mroz, 1999; Gauthier, 2002).

Já os fitogênicos como os óleos essenciais são compostos bioativos (líquidos oleosos, aromáticos e voláteis) oriundos de partes das plantas como flores, folhas, brotos, galhos, ervas, raízes, frutas, sementes, cascas e madeira; extraídos através da destilação a vapor e/ou água (Omonijo et al., 2017). Aproximadamente 3000 tipos de óleos essenciais são conhecidos atualmente, sendo que somente 300 são comercialmente importantes e utilizados, principalmente no mercado de sabores e fragrâncias (Van de Braak \& Leijten, 1999). Geralmente os óleos essenciais são reconhecidos como seguros pela Food and Drug Administration (FDA), órgão regulador dos Estados Unidos da América.

Como tratado, os ácidos orgânicos e os fitogênicos, além de atuarem como bactericidas, bacteriostáticos e moduladores da microbiota intestinal, possuem diversas outras funções, servindo como conservantes de alimentos, fonte de energia, potencializadores da utilização de minerais e nutrientes, estimuladores da secreção de enzimas endógenas e do desenvolvimento intestinal, antioxidantes (que melhoram a conservação e a qualidade de produtos cárneos e rações), antiinflamatórios e melhoradores da palatabilidade; promovendo o consumo de ração, com resultados subsequentes sobre a melhora da digestibilidade, da conversão alimentar e do metabolismo dos nutrientes (Papatsiros et al., 2012; Dhifi et al., 2016; Chouhan et al., 2017; Long et al., 2017; Omonijo et al., 2017; Simitzis, 2017).

\section{Modo de ação dos ácidos orgânicos}

Os ácidos orgânicos podem atuar como conservantes de alimentos e fonte de energia, ou ainda melhorando a utilização de minerais e nutrientes, estimulando a secreção de enzimas endógenas e a morfologia intestinal (Partanen \& Mroz, 1999). 


\section{Conservantes de alimentos e intensificadores de sabor}

Em geral os ingredientes utilizados na elaboração das rações, como grãos e alguns produtos de origem animal, têm alguma contaminação microbiana presente (bactérias, fungos e protozoários), sendo esta oriunda da planta ainda na lavoura e/ou decorrente de condições desfavoráveis durante seu armazenamento. Como são substratos ricos nutricionalmente, estes ingredientes e a própria ração suportam o crescimento destes agentes, que podem gerar danos aos animais quando são diretamente ingeridos ou indiretamente através de suas toxinas. Neste cenário, os ácidos orgânicos e seus derivados são frequentemente utilizados como conservantes devido às alterações que promovem no alimento pela queda do $\mathrm{pH}$ que imprimem, gerando um meio inapropriado para o desenvolvimento microbiano (Papatsiros \& Billinis, 2012). Neste caso a contaminação inicial de um alimento pode ser minimizada pela adição de ácidos antes e durante seu processamento (Dixon \&, 1981; Quitmann et al., 2013).

Outro fator importante na conservação de alimentos se deve ao potencial dos ácidos orgânicos e de seus derivados em atuar como antioxidantes ou em sinergia com este efeito. Os ácidos fenólicos, como o ácido gálico ou ácido ferúlico e seus derivados, atuam como antioxidantes primários. Já o ácido ascórbico e o ácido cítrico, bem como seus derivados, são exemplos de substâncias sinérgicas, pois melhoram a estabilidade do antioxidante primário e dos lipídios, acidificando o meio. Além disso, desativam íons metálicos pró-oxidantes, como ferro e o cobre, formando quelatos. $\mathrm{O}$ ácido ascórbico e seus derivados podem também eliminar o oxigênio e regenerar antioxidantes primários, como os tocoferóis (Quitmann et al., 2013).

Outra particularidade destes aditivos é a capacidade que têm em melhorar a palatabilidade dos alimentos, intensificando o sabor sem efetivamente imprimir um perfil ácido próprio, equilibrando com a sua acidez o sabor doce de um alimento (Quitmann et al., 2013), aumentando o interesse dos animais, o consumo e consequentemente o desempenho (Lei et al., 2017; Luise et al., 2017). No entanto, considera-se que altos níveis dietéticos de certos ácidos orgânicos podem reduzir substancialmente a palatabilidade da dieta e afetar o consumo de ração dos suínos (Rudbäck, 2013), sendo que o ácido cítrico e os ácidos tartárico e fórmico podem implicar negativamente no consumo dos leitões por apresentarem cheiro e sabor muito acentuado. Todavia, esta inferência no consumo pode estar mais relacionada à faixa etária dos suínos, em que leitões mais jovens são mais propensos a sentirem as mudanças de palatabilidade na ração (Partanen \& Mroz, 1999).

\section{Estimulantes da secreção de enzimas endógenas}

Os ácidos orgânicos atuam diretamente na estimulação da secreção de enzimas devido a influência sobre a secreção pancreática e biliar, além de servirem como substratos para o metabolismo intermediário, contribuindo para a melhora da digestão, da absorção e do aproveitamento dos nutrientes dietéticos (Thaela et al., 1998). Os mecanismos de ação propostos incluem a redução ou estabilização do $\mathrm{pH}$ gástrico, resultando em aumento da atividade das enzimas proteolíticas e do tempo de retenção gástrica, melhorando, portanto, a digestão proteica e consequentemente de aminoácidos (Partanen \& Mroz, 1999).

\section{Absorção de minerais}

A absorção de minerais também pode ser melhorada pela inclusão de ácidos orgânicos na dieta, pois os ânions destes ácidos podem formar complexos com o cálcio, fósforo, magnésio e zinco, incrementando a digestão desses minerais e reduzindo a excreção de minerais suplementares e do nitrogênio (Partanen \& Mroz, 1999; Suiryanrayana \& Ramana, 2015). Do mesmo modo, uma diminuição no $\mathrm{pH}$ intestinal é favorável para a solubilidade de alguns minerais, especialmente para o fósforo, melhorando sua absorção (Jongbloed et al., 2000), mas ainda há divergências sobre a redução do pH no trato gastrointestinal. Li et al. (2008) relataram que a utilização dos ácidos butírico, fumárico e benzóico a $0,5 \%$ e $1 \%$ não promoveu redução do $\mathrm{pH}$ da digesta no estômago, duodeno, jejuno e íleo de leitões desmamados.

\section{Ação sobre a microbiota e a morfologia intestinal}

Quanto aos efeitos clássicos antibacterianos dos ácidos orgânicos na microbiota intestinal são atribuídos dois mecanismos: a redução do $\mathrm{pH}$ dos alimentos e do sistema digestório, criando um 
ambiente negativo para o crescimento de microrganismos patogênicos; e o efeito antimicrobiano específico devido a forma não dissociada dos ácidos, o que leva à alteração de diversos processos essenciais para a vida destes agentes (Partanen \& Mroz, 1999; Davidson \& Taylor, 2007). Estas ações conduzem à modulação da microbiota do trato gastrintestinal, favorecendo as bactérias benéficas em detrimento das patogênicas (Namkung et al. 2004), provendo melhores condições de saúde, morfologia intestinal, digestão, aproveitamento alimentar e desempenho zootécnico.

Os ácidos orgânicos também podem influenciar a morfologia da mucosa intestinal através da estimulação direta sobre a proliferação das células epiteliais, melhorando a relação da altura das vilosidades e da profundidade das criptas (Dibner \& Buttin, 2002). Vilosidades mais longas indicam maior capacidade de absorção, maior produção enzimática e mais saúde do intestino, com resultados superiores no desempenho e no controle da diarreia (Pluske et al., 1997).

Sob uma ótica convergente com a qualidade intestinal, Grilli et al. (2010), utilizando ácidos orgânicos microencapsulados (ácido cítrico e ácido ascórbico) na ração de leitões desmamados, observaram uma maior produção de ácidos graxos voláteis (AGV) no intestino grosso. A rápida absorção desses ácidos graxos do cólon dos suínos, junto com as altas concentrações normalmente presentes como resultado da digestão microbiana do carboidrato solúvel, sugere que os AGV podem fornecer uma importante fonte de energia para esses animais (Argenzio \& Southworth, 1975). Os AGV representam uma fonte importante de energia para os enterócitos e tecidos adjacentes, além de atuarem na redução de processos inflamatórios e na diminuição do crescimento de bactérias patogênicas (Blaut \& Clavel, 2007; Richards et al., 2005). Neste particular, o ácido butírico é a principal fonte de energia para as células epiteliais do intestino grosso, guardando alta eficiência na promoção do desenvolvimento epitelial (Gálfi \& Bokori, 1990).

Callegari et al. (2016) verificaram que o uso de diferentes misturas e doses de ácidos orgânicos microencapsulados foram efetivos no controle da diarreia de leitões desmamados, sendo que as dietas com ácidos (comparadas com dietas isentas destes) promoveram a redução do $\mathrm{pH}$ gástrico e o aumento da produção de AGV no ceco, principalmente quando associada aos óleos essenciais.

\section{Modo de ação dos fitogênicos}

Os fitogênicos possuem vários compostos ativos que têm efeitos benéficos para animais e seres humanos, como o aumento das secreções digestivas; melhora da digestão e absorção de nutrientes, preservação da integridade da mucosa intestinal, estimulação do sistema imunológico e ações antibacterianas, coccidiostáticas, anti-helmínticas, anti-inflamatórias e antioxidantes (Brenes \& Roura, 2010; Suiryanrayana, 2015).

\section{Atividade antioxidante}

Diversas plantas e óleos essenciais (OEs) são conhecidos por suas propriedades antioxidantes, devido aos compostos fenólicos e a outros, como os flavonoides (encontrados em orégano e tomilho) e os osterpenoides (timol, carvacrol e eugenol, princípios ativos de tomilho, orégano e cravo, respectivamente), que atuam protegendo os alimentos, os tecidos e as células contra os efeitos deletérios da oxidação (Franz et al., 2010; Costa et al., 2013).

A oxidação lipídica dos produtos cárneos, em graus variados, resulta na formação de compostos que imprimem sabores desagradáveis, restringindo a aceitação pelos consumidores (Lee \& Shibamoto, 2002). Estes compostos, portanto, podem ser adicionados à carne ou aos seus produtos e à dieta dos animais, substituindo os aditivos sintéticos utilizados para este fim (Racanicci et al., 2004). Hanczakowska et al. (2015) observaram que a utilização de uma mistura de extratos de ervas (sálvia, urtiga, bálsamo de limão e echinácea), adicionada na ração de suínos em fase de engorda, melhorou significativamente a estabilidade oxidativa na carne, diminuiu o teor de colesterol e aumentou o nível de ácidos graxos polisaturados.

\section{Atividade anti-inflamatória}

A inflamação é uma resposta nata de proteção dos animais induzida pela lesão tecidual, podendo ser biológica, química ou física, e que tem como objetivo a eliminação dos microrganismos invasores e a 
remoção de células hospedeiras mortas ou danificadas (Stevenson \& Hurst, 2007). No entanto, às vezes, a inflamação pode persistir por mais tempo do que é necessário, causando mais danos do que benefícios (Ashley et al., 2012). Felizmente, existem inúmeras maneiras de controlar a inflamação e promover a saúde geral no processo.

Os fitogênicos são capazes de exercer atividade anti-inflamatória por alguns de seus compostos, por exemplo: limoneno, $\alpha$-terpineol, $\delta$-3-carene $\alpha$-pinene e 1,8-cineol. Estes compostos operam a partir da inibição da liberação de histamina e leucotrienos, reduzindo a produção de mediadores inflamatórios, inibição da ciclooxigenase-2 (COX-2), e consequentemente, inibindo a produção de prostaglandina, além de interações com as cascatas de sinalizações, envolvendo fatores regulatórios de transcrição e expressão de genes pró-inflamatórios (Dhifi et al., 2016), resultando em menores níveis plasmáticos de citocinas inerentes ao processo inflamatório (Vieira et al., 2014).

Em razão dos efeitos anti-inflamatórios que detém, os fitogênicos são adicionados às dietas de suínos com o objetivo de controlar a inflamação intestinal, que é inerente e constante, resultado da exposição contínua do órgão a vários agentes infecciosos, aos antígenos alimentares e aos desafios de manejo (Yang et al., 2015). Fiesel et al. (2014) relataram uma menor expressão de vários genes próinflamatórios na mucosa intestinal, além de um efeito benéfico na função absortiva do intestino (aumento da superfície de absorção) de suínos jovens suplementados com produtos de origem vegetal ricos em polifenóis. Em leitões desmamados, a suplementação dietética com o óleo de canela $(50 \mathrm{mg} / \mathrm{kg}$ dieta) reduziu significativamente as lesões induzidas pelo lipopolissacarídeo de Escherichia coli devido à supressão da inflamação, assim como também a redução do estresse oxidativo na mucosa intestinal (Wang et al., 2015). Também em frangos, a adição de doses baixas $(2-5 \mathrm{mg} / \mathrm{kg}$ dieta) de três compostos fitoquímicos derivados do orégano, canela e pimenta (carvacrol, cinamaldeído e capsicum respectivamente) induziu a modulação da resposta inflamatória resultando em melhor proteção contra coccidiose (Lillehoj et al., 2011).

\section{Palatabilidade, digestibilidade e desempenho}

Os fitogênicos, pelo odor e sabor que conferem à ração, promovem a melhora da palatabilidade e, por consequência, o aumento do consumo de alimento, em especial quando a espécie alvo é o suíno (Zeng et al., 2015). Também cabe renovar a atividade antioxidante que estes princípios têm, minimizando os processos oxidativos da dieta, que resultariam na presença de odores desagradáveis e na perda de palatabilidade (Sola-Oriol et al., 2011).

A melhoria da digestibilidade e da disponibilidade de nutrientes está relacionada com a capacidade que diversos compostos ativos dos óleos essenciais têm em aumentar a atividade enzimática, estimular secreções de bile, muco, glândulas salivares, suco gástrico e pancreático (Costa et al., 2013). Vários estudos associam o uso dos fitogênicos com a melhora na digestibilidade e desempenho. A adição de óleos essenciais microencapsulados de cravo, tomilho e orégano, acrescido dos princípios ativos eugenol e carvacrol induziu uma maior digestibilidade dos nutrientes dietéticos e melhora do desempenho de leitões recém-desmamados (Oetting, 2006). Resultados similares foram descritos na primeira semana pós-desmame em leitões que receberam dietas suplementadas com uma mistura de extratos de trigo mourisco, tomilho, curcuma, pimenta preta e gengibre a $250 \mathrm{mg} / \mathrm{kg}$ (Yan et al., 2012). Li et al. (2012) ao incluírem óleos essenciais encapsulados (timol e cinamaldeido) na dieta de leitões desmamados, verificaram uma melhora em todos os parâmetros de desempenho da fase, quando comparado com o grupo que não recebeu estes princípios.

De modo geral, há consenso de que os fitogênicos se mostram como uma excelente alternativa para melhorar a digestibilidade da dieta e para promover o ganho de peso após o desmame, uma fase crítica onde os leitões ainda são pouco eficientes fisiológica e enzimaticamente para aproveitar dietas diferentes do leite materno (Huang et al., 2010).

\section{Efeitos sobre a morfologia intestinal}

Os benefícios do uso de fitogênicos para suínos, em especial para leitões desmamados, se estendem às respostas na morfologia intestinal. Li et al. (2012) observaram uma melhora na relação da altura das vilosidades com a profundidade das criptas no jejuno de suínos alimentados com dietas contendo óleos 
essenciais em relação àqueles submetidos a uma dieta controle (isenta deste aditivo). Zou et al. (2016) verificaram que suínos tratados com óleos essenciais induziram uma diminuição do nível de endotoxina no soro e aumento da altura das vilosidades e na expressão de ocludina e zônula ocludens-1 (ZO-1) no jejuno (proteínas estas relacionadas com o estabelecimento da barreira entre os enterócitos, controlando o fluxo de moléculas no espaço intercelular entre as células do epitélio). Estes resultados indicam que há melhora da integridade da barreira intestinal quando os animais são expostos aos óleos essenciais na dieta. Estas mudanças na morfologia do intestino são acompanhadas pelo incremento da digestão e absorção de nutrientes, e menor ocorrência e intensidade de diarreias, promovendo assim mais ganhos.

\section{Considerações finais}

Os ácidos orgânicos e fitogênicos representam uma classe de aditivos que podem substituir os APC com êxito. Paralelamente, também têm uma amplitude de benefícios que se estendem desde a prevenção de contaminantes dietéticos a ações anti-inflamatórias, antioxidantes, palatabilizantes, moduladoras da microbiota e da renovação dos tecidos intestinais, entre outras.

Esta gama de efeitos amplia seu potencial e uso e sinaliza para possíveis associações com outras classes de aditivos. Neste sentido, os novos desafios decorrentes da retirada dos APC das rações de animais de produção, tornam-se menores diante das virtudes dessas duas amplas classes de produtos.

\section{Referências}

Argenzio, R. \& Southworth, M. (1975). Sites of organic acid production and absorption in gastrointestinal tract of the pig. American Journal of Physiology, 228(2): 454-460

Ashley, N. T., Weil, Z. M. \& Nelson, R. J. (2012). Inflammation: Mechanisms, costs, and natural variation. Annual Review of Ecology, Evolution, and Systematics, 43(1):385-406.

Blaut, M. \& Clavel, T. (2007). Metabolic diversity of the intestinal microbiota: implication for health and disease. The Journal of Nutrition, 137(3): 751S-755S.

Brenes, A. \& Roura, E. (2010). Essential oils in poultry nutrition: Main effects and modes of action. Animal Feed Science and Technology, 158(1-2): 1-14.

Callegari, M. A., Ketilim Novais, A., Raele Oliveira, E., Pazinato Dias, C., Laurinha Schmoller, D., Pereira Junior, M., Dário, J. G. N., Alves, J. B. \& Silva, C. A. (2016). Microencapsulated acids associated with essential oils and acid salts for piglets in the nursery phase. Semina: Ciencias Agrárias, 37(4):2193-2208.

Chouhan, S., Sharma, K. \& Orcid, S. G. (2017). Antimicrobial activity of some essential oils-Present status and future perspectives. Medicines, [s.1.], 4(3):58-79.

Costa, L. B., Luciano, F. B., Miyada, V. S. \& Gois, F. D. (2013). Herbal extracts and organic acids as natural feed additives in pig diets. South African Journal of Animal Science, 43(2):181-193.

Davidson, P. M. \& Taylor, T. M. (2007). Chemical Preservatives And Natural Antimicrobial Compounds. Food Microbiology: Fundamentals and Frontiers, Third Edition. p.713-745, 2007. American Society of Microbiology.

Dhifi, W., Bellili, S., Jazi, S., Bahloul, N., \& Mnif, W. (2016). Essential Oils' Chemical Characterization and Investigation of Some Biological Activities: A Critical Review. Medicines, 3(4):25-41.

Dibner, J. J. \& Buttin, P. (2002). Use of Organic Acids As A Model To Study The Impact Of Gut Microflora On Nutrition And Metabolism. Journal of Applied Poultry Research, 11:453-463.

Dixon, R. C. \& Hamilton, P. B. (1981). Evaluation of some organic acids as mold inhibitors by measuring $\mathrm{CO}_{2}$ Production from Feed and Ingredients. Poultry Science, 60(10):2182-2188.

Fiesel, A., Gessner, D. K., Most, E. \& Eder, K. (2014). Effects of dietary polyphenol-rich plant products from grape or hop on pro-inflammatory gene expression in the intestine, nutrient digestibility and faecal microbiota of weaned pigs. BMC Veterinary Research, 10(1):196.

Franz, C., Baser, K. H. C. \& Windisch, W. (2010). Essential oils and aromatic plants in animal feeding - a European prespective. Flavour and Fragrance Journal, 25:327-340.

Gálfi, P. \& Bokori, J. (1990). Feeding trial in pigs with a diet containing sodium n-butyrate. Acta veterinaria Hungarica, 38(1-2):3-17. 
Gauthier, R. (2002). The mode of action of acidifiers and the interest they generate in the growingfinishing phase. Current developments in pig production, 16.

Grilli, E., Messina, M. R., Tedeschi, M. \& Piva, A. (2010). Feeding a microencapsulated blend of organic acids and nature identical compounds to weaning pigs improved growth performance and intestinal metabolism. Livestock Science, 133(1-3):173-175.

Hanczakowska, E., Świtkiewicz, M. \& Grela, E. R. (2015). Effect of dietary inclusion of a herbal extract mixture and different oils on pig performance and meat quality. Meat Science, [s.1.], 108, p.61-66.

Huang, Y., Yoo, J. S., Kim, H. J., Wang, Y., Chen, Y. J., Cho, J. H., \& Kim, I. H. (2010). Effects of dietary supplementation with blended essential oils on growth performance, nutrient digestibility, blood profiles and fecal characteristics in weanling pigs. Asian-Australasian Journal of Animal Sciences, 23(5):607-613.

Jongbloed, A, Mroz, Z., Weij-Jongbloed, R. Van Der \& Kemme, P. (2000). The effects of microbial phytase, organic acids and their interaction in diets for growing pigs. Livestock Production Science, 67(1-2): 113-122.

Lee, K. G. \& Shibamoto, T. (2002). Determination of antioxidant potential of volatile extracts isolated from various herbs and spices. Journal of Agricultural and Food Chemistry, 50(17):4947-4952.

Lei, X. J., Park, J. W., Baek, D. H., Kim, J. K., \& Kim, I. H. (2017). Feeding the blend of organic acids and medium chain fatty acids reduces the diarrhea in piglets orally challenged with enterotoxigenic Escherichia coli K88. Animal Feed Science and Technology, 224:46-51.

Li, Z., Yi, G., Yin, J., Sun, P., Li, D., \& Knight, C. (2008). Effects of organic acids on growth performance, gastrointestinal $\mathrm{pH}$, intestinal microbial populations and immune responses of weaned pigs. Asian-australasian Journal of Animal Sciences, 21(2): 252-261.

Li, P., Piao, X., Ru, Y., Xue, L. \& Zhang, H. (2012). Effects of adding essential oil to the diet of weaned pigs on performance, nutrient utilization, immune response and intestinal health. Asian-Australasian Journal of Animal Science, 25: 1617-1626.

Lillehoj, H. S., Kim, D. K., Bravo, D. M. \& Lee, S. H. (2011). Effects of dietary plant-derived phytonutrients on the genome-wide profiles and coccidiosis resistance in the broiler chickens. BMC Proceedings, 5(Suppl 4): S34.

Long, S. F., Xu, Y. T., Pan, L., Wang, Q. Q., Wang, C. L., Wu, J. Y., Piao, X. S. (2017). Mixed organic acids as antibiotic substitutes improve performance, serum immunity, intestinal morphology and microbiota for weaned piglets. Animal Feed Science and Technology, 235: 23-32.

Luise, D., Motta, V., Salvarani, C., Chiappelli, M., Fusco, L., Bertocchi, M., Mazzoni, M., Maiorano, G., Costa, L. N., Milgen, J. V. \& Bosi, P. (2017). Long-term administration of formic acid to weaners: Influence on intestinal microbiota, immunity parameters and growth performance. Animal Feed Science and Technology, 232:160-168.

Namkung, H., Li J. Gong, M., Yu, H., Cottrill, M., \& De Lange, C. F. M. (2004). Impact of feeding blends of organic acids and herbal extracts on growth performance, gut microbiota and digestive function in newly weaned pigs. Canadian Journal of Animal Science, 84(4):697-704.

Oetting, L. L., Utiyama, C. E., Giani, P. A., Ruiz, U.S., Miyada, V. S. (2006). Efeitos de extratos vegetais e antimicrobianos sobre a digestibilidade aparente, o desempenho, a morfometria dos órgãos e a histologia intestinal de leitões recém-desmamados. Revista Brasileira de Zootecnia, 35(4): 1389-1397.

Omonijo, F. A., Ni, L., Gong, J., Wang, Q., Lahaye, L., Yang, C. (2017). Essential oils as alternatives to antibiotics in swine production. Animal Nutrition,.1-11.

Papatsiros, V. G. \& Billinis, C. (2012). The prophylactic use of acidifiers as antibacterial agents in swine. In:. Antimicrobial agents. Dr. Varaprasad Bobbarala (Ed.). InTech, Rijeka, Croatia, p. 295-310.

Papatsiros, V. G., Christodoulopoulos, G. \& Filippopoulos, L. C. (2012). The use of organic acids in monogastric animals (swine and rabbits). Journal of Cell and Animal Biology, 6(10):154-159.

Partanen, K. H. \& Mroz, Z. (1999). Organic acids for performance enhancement in pig diets. Nutrition Research Reviews, 12(01), 117. https://doi.org/10.1079/095442299108728884

Paul, S., Samanta, G., Halder, G., \& Biswas, P. (2007). Effect of a combination of organic acid salts as antibiotic replacer on the performance and gut health of broiler chickens. Livestock Research for Rural Development, 19(11). 
Pluske, J. R., Hampson, D. J., Williams, I. H. (1997). Factors influencing the structure and function of the small intestine in the weaned pig: a review. Livestock Production Science, 51(1-3): 215-236.

Quitmann H., Fan R. \& Czermak P. (2013). Acidic organic compounds in beverage, food, and feed production. In: Zorn H., Czermak P. (eds). Biotechnology of Food and Feed Additives. Advances in Biochemical Engineering/Biotechnology, vol 143. Springer, Berlin, Heidelberg:91-141.

Racanicci, A. M., Danielsen, B., Menten, J. F. M., Regitano-D'arce, M. A., \& Skibsted, L. H. Antioxidant effect of dittany (Origanum dictamnus) in pre-cooked chicken meat balls during chillstorage in comparison to rosemary (Rosmarinus officinalis). European Food Research and Technology, 218(6):521-524, 2004.

Richards, J. D., Gong, J. \& Lange, C. F. M. (2005). The gastrointestinal microbiota and its role in monogastric nutrition and health with an emphasis on pigs: current understanding, possible modulations, and new technologies for ecological studies. Canadian Journal of Animal Science, 85(4): 421-435.

Rudbäck, L. (2013). Organic acids in liquid feed for pigs - palatability and feed intake. SLU, Dept. of Animal Nutrition and Management.

Russell, J. B. (1992). Another explanation for the toxicity of fermentation acids at low $\mathrm{pH}$ : anion accumulation versus uncoupling. Journal of Applied Bacteriology, 73(5), 363-370. https://doi.org/10.1111/j.1365-2672.1992.tb04990.x

Simitzis, Panagiotis E. (2017). Enrichment of animal diets with essential oils - A great perspective on improving animal performance and quality characteristics of the derived products. Medicines, 4(2):35-56.

Sola-Oriol, D., Roura, E. \& Torrallardona, D. (2011). Feed preference in pigs: Effect of selected protein, fat, and fiber sources at different inclusion rates. Journal of Animal Science, 89(10):3219-3227.

Stevenson, D. E. \& Hurst, R. D. (2007). Polyphenolic phytochemicals - just antioxidants or much more? Cellular and Molecular Life Sciences, 64(22): 2900-2916.

Suiryanrayna, M. V. A. N., Ramana, J. V. (2015). A review of the effects of dietary organic acids fed to swine. Journal of Animal Science and Biotechnology, 6(1): 45.

Thaela, M.-J., Jensen, M., Pierzynowski, S., Jakob, S., \& Jensen, B. (1998). Effect of lactic acid supplementation on pancreatic secretion in pigs after weaning. Journal of Animal and Feed Sciences, 7(Suppl. 1), 181-183. https://doi.org/10.22358/jafs/69972/1998

Van De Braak, S. A. A. J. \&Leijten, G.C.J.J. (1999). Essential oils and oleoresins: A survey in the Netherlands and other major markets in the European Union. CBI, Centre for the Promotion of Imports from Developing Countries, Rotterdam, 116.

Vieira, N. A., Tomiotto, F. N., Melo, P. G., Manchope, M. F; Lima, N. R., Oliveira, G. G. \& Watanabe, M. A. E. (2014). Efeito anti-inflamatório do gengibre e possível via de sinalização. Semina: Ciências Biológicas e da Saúde, 35(1):149-162.

Yan, L., Meng, Q.W. \& Kim, I.H. (2012). Effect of an herb extract mixture on growth performance, nutrient digestibility, blood characteristics, and fecal microbial shedding in weanling pigs. Livestock Science, 145(1-3):189-195.

Yang, C., Chowdhury, M. A., Huo, Y., \& Gong, J. (2015). Phytogenic compounds as alternatives to in feed antibiotics: Potentials and challenges in application. Pathogens, 4(1):137-156.

Zeng, Z., Zhang, S., Wang, H., \& Piao, X. (2015). Essential oil and aromatic plants as feed additives in non-ruminant nutrition: a review. Journal of Animal Science and Biotechnology, 6(1):7-17.

Zou, Y., Xiang, Q., Wang, J., Peng, J., Wei, H. (2016). Oregano essential oil improves intestinal morphology and expression of tight junction proteins associated with modulation of selected intestinal bacteria and immune status in a pig model, Biomed Research International, 2016, ID 5436738 .

Wang, L., Hou, Y., YI, D. (2015). Beneficial roles of dietary oleum cinnamomi in alleviating intestinal injury. Frontiers in Bioscience, 20:814-28.

Histórico do artigo:

Recebido: 17 de dezembro de 2020.

Aprovado: 16 de janeiro de 2021.
Licenciamento: Este artigo é publicado na modalidade Acesso Aberto sob a licença Creative Commons Atribuição 4.0 (CC-BY 4.0), a qual permite uso irrestrito, distribuição, reprodução em qualquer meio, desde que o autor e a fonte sejam devidamente creditados. 